\title{
The Effects of Aquatic Group Exercise on Body Composition and Mental Health of Elderly Women
}

\author{
Hae-An OK ${ }^{\dagger}$
}

Dept. of Sports and Health Management, Mokwon Univiersity

Received: December 7, 2016 / Revised: December 27, 2016 / Accepted: February 2, 2017

(c) 2017 J Korean Soc Phys Med

\begin{abstract}
| Abstract |
PURPOSE: Regular physical activity in the elderly population has significant benefits for health. The purpose of this study was to investigate the effects of aquatic group exercise on body composition and mental health of the elderly females.
\end{abstract}

METHODS: This study included 40 elderly women. The aquatic group exercise program was performed for an hour a day, 3 times a week for 12 weeks with moderate-intensity level. The body composition, physical fitness mental health instruments were used to measure the outcome variables before and after the program. Data was analyzed with SPSS using descriptive statistics and the t-test.

RESULTS: It was found that the 12 week aquatic group exercise program had effects on body mass and BMR were significantly improved after the intervention of this study. In health related physical fitness, flexibility and sense of balance were significantly increased in the participants. In the mental health of the female elderly participants were evaluated in areas such as depression, sense of isolation, interpersonal

†Corresponding Author : Haean.ok@gmail.com

This is an Open Access article distributed under the terms of the Creative Commons Attribution Non-Commercial License (http://creativecommons.org/licenses/by-nc/3.0) which permits unrestricted non-commercial use, distribution, and reproduction in any medium, provided the original work is properly cited. anxiety, and sociality. They showed significant change in a positive way.

CONCLUSION: It is suggested that aquatic group exercise should be activated and encouraged to enhance physical and mental health of elderly women and various types of manuals should be developed according to characteristics of programs to operate this exercise more effectively.

Key Words: Aquatic group exercise, Body mass index, Elderly women, Mental health, Physical fitness

\section{Introduction}

The elderly population over 65 is increasing every year in Korea by $12.7 \%$ as indicated by a study conducted in 2014. If adding pre-elderly, those who were born between 1955 and 1963, during baby boom, the elderly and pre-elderly population reaches $33.5 \%$ (Statistics Korea, 2015). Such a rapid increase of the elderly population creates various social problems in the area of jobs, leisure, medical services, and also welfare (Kim, 2009). Prevalence of disease among Korean elderly is constantly increasing just like the trend of the aged population according to National Statistics (Statistics Korea, 2015). Especially medical expenses of the elderly over 65 in 2013 reached 
$17,528.3$ billion won which is $34.5 \%$ of total medical expenses which is $50,742.6$ billion won.

Remarkable medical improvement brought a longer average life expectancy. As living in the area of longevity, higher level of fitness is an essential and important factor for mental, social, and the quality of life. Therefore, the meaning of attending physical activities in the elderly is more important than in the young population (Williams et al., 1993). Particularly, active participation of the elderly in their physical activities will benefit not only themselves but also society (Reaven et al., 1991; Lee and Park, 2013).

According to World Health Organization (WHO), regular physical activity of moderate intensity in the elderly population has significant benefits for a happy life as well as physical, social, and mental health (WHO, 2016). Compared with inactive elderly, the active had relatively lower prevalence in many diseases such as depression, cardiac disease, hypertension, stroke, type II diabetes, metabolic syndrome, rectal colon, and breast cancer. Furthermore, it was reported that higher attendance of physical activities would restrain the aging process, and also prevents various geriatric illnesses (WHO, 2016).

It has been recommended that elderly and obese females reduce ground exercises and to increase aquatic exercise which would not be a burden while improving muscular power and widening the working range of joints (Choi et al., 2012; Jung et al., 2010; Lee et al., 2004). It is also reported that these exercises have beneficial effects on body composition (Park and Ahn, 2010), basic physical fitness factors such as improvement in muscular strength, flexibility, sense of balance, muscular endurance, increase of joint working range, and better quality of life (Jang, 2000; Kim and Kim, 2013; Lee et al., 2011; You and Lee, 2010).

Aquatic group exercise is one of the recommendable physical activities for the elderly. Especially, for surgical rehabilitation patients, the elderly, those who have weak physical fitness or those who are obese. Aquatic exercise prevents overload on the body while increasing the amount and strength of muscle, and flexibility of joints (Kim et al., 2016; Lee et al., 2004).

Besides, recently such aquatic group exercise is evolving into new types of highly recommendable activities with recreational characteristics. Aquatic group exercise is a series of planned and programmed underwater exercises composed of various movements and games accompanied with the newest popular music rather than existing rehabilitation focused underwater exercise. Such aquatic group exercise improves not only health and strength of the elderly but also enhances their social activities. Therefore, the elderly who participated in these exercises can improve or prevent mental illnesses such as isolation, depression, helplessness, and a sense of alienation by sympathizing and interacting with one another (Cho and Kim, 2012; Moon, 2014).

Nevertheless, there have not been many studies on the effects of aquatic group exercise on the change of body composition, and basic physical fitness. In particular, studies about effects of such aquatic group exercise on social wellbeing and mental health of the elderly have not been presented and studied (Song et al., 2011). Therefore, this study tries to identify effects of Aquatic group exercise for 12 weeks on body composition, basic physical fitness, as well as mental health of the elderly.

\section{Method}

\section{Subjects}

The subjects of the study were 40 females from 65 to 80 years old who enrolled in aquatic group exercise for the first time in 4 swimming pools in D metro city. All the subjects were medically fit enough to participate in underwater exercise. The criteria for selection of the subjects in this study were those who agreed to participate in the aquatic exercise program, those who were able to 
communicate and did not have cognitive impairment, those who did not have chronic diseases and physical defects or cardiopulmonary disorders that interfere with exercise, and was limited to those who did not participate in physical exercise or other exercise programs for the previous 6 months. And, for the ethical issue, the study was conducted after obtaining the participation agreement and were used a pseudonym to protect the identity and personal information. Their general characteristics are shown in (Table 1).

Table 1. General Characteristics of Subjects $(\mathrm{N}=40)$

\begin{tabular}{cccc}
\hline $\begin{array}{c}\text { Age } \\
(\mathrm{yr})\end{array}$ & $\begin{array}{c}\text { Height } \\
(\mathrm{cm})\end{array}$ & $\begin{array}{c}\text { Body } \\
\text { Weight } \\
(\mathrm{kg})\end{array}$ & $\begin{array}{c}\text { Percent } \\
\text { Body Fat } \\
(\%)\end{array}$ \\
\hline $68.87 \pm 8.52$ & $154.16 \pm 5.39$ & $62.32 \pm 7.67$ & $36.10 \pm 6.16$ \\
\hline
\end{tabular}

\section{Aquatic Group Exercise Program}

The length of the pool is 5 lanes with a length of 25 $\mathrm{m}$ and a depth of 1.2 to $1.4 \mathrm{~m}$. The pool was kept at room temperature $28.5 \sim 29{ }^{\circ} \mathrm{C}$, relative humidity $60 \sim 70 \%$, water temperature $28 \sim 30{ }^{\circ} \mathrm{C}$. In order to disinfect the swimming pool, it is the only safe chlorine currently used in Korea, and the concentration is .4 1.0ppm, which was to be automatically supplied to the concentration range by a computerized system the machine. In order to prevent safety accidents at the swimming pool during the class, the security officer was on duty at all times.

A total of 12 weeks of aquatic group exercise program was performed three times a week for 60 minutes per day, and it was conducted in the order of warm up exercise, main exercise, and cool down exercise as shown in (Table 2). The pool lighting was 200 500 Lux, which is the general indoor pool lighting according to the illumination standard. The objective of the warm up exercise is to create a state of mind and body that can raise the effectiveness of primary movements.

To maintain a normal body temperature, this study used 10 minutes to walk slowly in the water (front, side, back),

Table 2. Aquatic Group Exercise Program

\begin{tabular}{|c|c|c|}
\hline Categories & Exercises & Intensity \\
\hline $\begin{array}{l}\text { Warm Up } \\
\text { (10 min.) }\end{array}$ & $\begin{array}{l}\text { - Walking, Articulation exercises, Stretching. } \\
\text { - Bounce-front, back, side(Tempo-half water tempo. water tempo) } \\
\text { - Knee jogging-narrow wide cross. } \\
\text { - Jumping jack, Scissors, Pendulum leg swing, Leaping, Leg Curl, Twist, Mambo } \\
\text { step, jazz kick\& soccer kick, Kick-front, back, side. } \\
\text { - Frog jump, Tuck jump, Land jogging (Level 1, 2, 3), } \\
\text { - Push and Jumping jack 8, }\end{array}$ & RPE 9 - 11 \\
\hline $\begin{array}{l}\text { Primary } \\
\text { Exercise } \\
\text { (40 min.) }\end{array}$ & $\begin{array}{l}\text { - Push } 4 \text { count } 2 \text { times and Jogging with chest shake } 8 \text { count), } \\
\text { - (Push } 8 \text { count } 2 \text { times and Land jogging } 8 \text { count } \\
\text { - (Rock step- } 8 \text { count) and (Wide Kick right to left side } 8 \text { count) } \\
\text { - (Rock step-left to right side } 8 \text { count) }+ \text { (Wide Kick left side } 8 \text { count) } \\
\text { - (Push-from left foot } 8 \text { count) and turn(Push-right foot } 8 \text { count) } \\
\text { - Free style Pyramid, and Pattern style proceed with music and basic movement. } \\
\text { - Shoulder Movement (Shoulder flexion, extension, adduction, abduction, external and } \\
\text { internal rotation, bicep curl) }\end{array}$ & RPE $11-13$ \\
\hline $\begin{array}{c}\text { Cool Down } \\
\text { (10 min.) }\end{array}$ & - Static and dynamic stretching. & RPE $9-11$ \\
\hline
\end{tabular}


arm waving, fast walking, and simple articulation as well as dynamic stretching. Also, a beat that is important for the movement of the subjects in the aquatic exercise and was designated at a speed of 110-130 bpm, while the warm and cooldown exercise was performed at $110 \mathrm{bpm}$.

In this exercise, using a rating of perceived exertion (RPE), the intensity of the adaptation was 9 10 (very light) for the first week, and 11 12 (light) for the second week. The progressive increase method was applied to the exercise intensity of 11 13 (a little hard or hard). Exercises include making a circle for recreational game by pushing the side of the water, holding hands and clapping hands, and hip-dancing with hip-bumping. Next, to improve muscle strength and endurance, exercise was performed with an aqua rod to increase resistance. Finally, aerobic group exercise was performed by jogging or fast beat dancing.

The cool down exercise was performed with static and dynamic stretching for 10 minutes. Static stretching was stretched slowly by stretching, pulling and then held for 15 seconds.

\section{Measurement}

\section{1) Body Composition Analysis}

(1) InBody Measurement

Body composition such as muscle amount, basal metabolic rate, percentage of body fat, and BMI (Body Mass Index, $\mathrm{kg} / \mathrm{m} 2$ ) was measured by In-body 230 (Biospace, Korea).

To verify the reliability of the InBody, So et al. (2012) conducted a study to compare body composition measurements taken with air displacement plethysmography (BOD POD) using eight-polar bioelectrical impedance analysis. Pearson's $r$ correlation showed that body composition measurements taken using the BOD POD and the eight polar BIA including InBody correlated significantly with respect to fat free mass $(\mathrm{r}=.911)$; (fat mass $\mathrm{r}=.938$ ); and $\%$ body fat $(\mathrm{r}=.871)$.
(2) Basal Metabolic Rate (BMR)

The basal metabolic rate is the energy consumed to maintain fundamental life phenomena such as nerve action, circulation, respiration, endocrine, digestion, body temperature maintenance and other cell action. According to Lim's (2016) study on the body composition, physical activity level, basal metabolic rate, and daily energy expenditure (DEE) of the elderly in Busan, DEE was calculated by H-B formula, DRI formula, Inbody measurement, and estimated energy requirements (EER) formula. The correlation was found to be significantly high between .73 and .89 .

\section{2) Basic Physical Fitness}

(1) Muscular Strength (Grip Strength) Measurement

Choe et al.'s (2010) study on the evaluation of the Korean Version of Physical Activity Scale for the Elderly (K-PASE) developed the K-PASE, which can more easily and accurately measure physical activity of the elderly. This tool was developed by Washburn et al. (1993). Validity and reliability were verified through previous studies while the test-retest reliability was assessed over a 2 week interval $(\mathrm{r}=.94)$. The grip strength was measured in $\mathrm{kg}$ units using the Lafayette Instrument tool (USA). This study instructed that the arm be held firmly by the usual hand using the usual hand in the stance with 15 degrees apart to allow the body to fall 15 degrees and to open the legs naturally and then read the scale indicated by the needle while selecting the maximum value out of two trials.

\section{(2) Flexibility Measurement}

The flexibility measure (sit \& reach) used in this study is based on the SFT (Senior Fitness Test) method developed by Rikli and Jones (2001) of the California State University. Based on the reference value obtained by measuring over 7,000 people aged 60 to 94 years, moreover it has been reported that it meets scientific criteria for reliability and 
validity. The measurement of this study was conducted while taking precautions including careful alignment of the fingertips of both hands, avoiding bending forward with the recoil, placing the head between the arms when bending forward, and not bending the knee. From conducting the measure two times, the better grade was recorded and the unit was recorded with two decimal places.

(3) Balance Measurement (One leg balance with eyes open) In order to evaluate the static equilibrium of the study participants, this study was conducted with participants standing on one leg with eyes open which was designed specifically for the elderly. This measurement method referred to the studies of Araki et al. (2002) and Resnick et al. (2000) and the presentation material by Moon (2014).

In the measurement method, the subject stands barefoot and puts both hands on his/her waist, and bends the knee of a convenient foot and takes a posture in which the foot is raised about $15 \mathrm{~cm}$ from the floor. Both eyes are opened with the start signal and the time that the balance is maintained is measured. The measurer stops the stopwatch when the subject's feet touch the floor, and either hand is released from the waist. From conducting the measure two times, the better result was recorded. The unit was expressed in seconds with the seconds rounded up. It is important that the knee of the line leg is not bent and that the body is not moved severely.

(4) Muscular Endurance (lying down and lifting up a leg for isometric endurance)

This study used the method to measure the muscular endurance of the entire flexor muscles of the abdomen designed by McGill (2002) and systemically utilized by Park et al. (2014). This study applied the slope at 30 to 40 degrees for the measurement. In the measurement, when the subject's pelvis, lumbar vertebra, thoracic vertebra, and head are in a comfortable and prostrated position with the legs being contracted, both feet are lifted with the start signal and the test ended when participants' leg touched the floor.

\section{3) Mental Health Measurement}

To identify the effects of the program on mental health, this study used 4 scales such as sense of isolation, depression, sociality, and interpersonal anxiety which was used as psychological and social change questionnaire in "Development of Silver Stretching program to Change Physical, Psychological and Social Health of the Elderly and Analysis of Its Effects" developed by Lim (2007). Each question ask about mental health and used the Likert 5 scale. The questionnaire is composed of 16 questions on sense of isolation ( $\alpha=.927), 17$ questions on depression ( $\alpha$ $=.923), 12$ questions on sociality ( $\alpha=.891$ ), and 14 questions on interpersonal depression $(\alpha=.885)$. Reliability was relatively high as shown in parenthesis.

\section{Data Analysis}

Using SPSS-18.0(Statistical Package for the Science, Inc., Chicago, IL, USA), mean and standard deviation were calculated. The effects of the variables used in this study were abstracted per factors and the matching sample t-test was executed to verify the mean difference in each factor before and after the aquatic group exercise program. Significance level was set as $\mathrm{p}<.05$.

\section{Results}

\section{Result of Body Composition Analysis}

When analyzing body composition before and after the 12 week aquatic group exercise program, it was found that there was significant change in body mass and basal metabolic rate $(\mathrm{BMR})$ as shown in (Table 3) $(\mathrm{p}<.01)$. Although there was change in BMI before and after program, it was not statistically significant. 
Table 3. Body Composition Analysis $(\mathrm{N}=40)$

\begin{tabular}{lcccc}
\hline \multirow{2}{*}{ Categories } & \multicolumn{2}{c}{ Mean \pm SD } & t & p \\
\cline { 2 - 5 } & Before & $23.07 \pm 2.81$ & -3.89 & $.01^{* *}$ \\
Body Mass (kg) & $21.66 \pm 3.75$ & $1286.50 \pm 29.82$ & -3.65 & $.01^{* *}$ \\
Basal Met. Rate (kcal) & $1234 \pm 10.22$ & $26.04 \pm 2.91$ & 1.58 & .11 \\
BMI $(\mathrm{kg} / \mathrm{m} 2)$ & $26.23 \pm 2.91$ & & &
\end{tabular}

$* \mathrm{p}<.05, \quad * * \mathrm{p}<.01$

\section{Result of Basic Physical fitness Analysis}

When analyzing basic physical fitness and after the 12 week aquatic group exercise program, it was found that there was significant change in flexibility and sense of balance as shown in (Table 4) $(\mathrm{p}<.01)$. However, there was no significant difference in muscular strength and muscular endurance in mean comparison.

\section{Result of Mental Health Analysis}

As shown in (Table 5), when analyzing mental health before and after the 12 week aquatic group exercise program, it was found that there was significant difference in all 4 factors such as sense of isolation, depression, sociality, and interpersonal anxiety as shown in Table 5 $(\mathrm{p}<.01)$.

\section{Discussion}

This study performed a 12 week aquatic group exercise program on the female elderly from 65 to 80 years old and analyzed changes in body composition, basic physical

Table 4. Basic Physical Fitness Analysis $(\mathrm{N}=40)$

\begin{tabular}{|c|c|c|c|c|}
\hline \multirow{2}{*}{ Categories } & \multicolumn{2}{|c|}{ Mean \pm SD } & \multirow{2}{*}{$\mathrm{t}$} & \multirow{2}{*}{$\mathrm{p}$} \\
\hline & Before & After & & \\
\hline Muscular Strength (kg) & $22.91 \pm 3.91$ & $23.72 \pm 3.53$ & -1.62 & .11 \\
\hline Flexibility (cm) & $13.20 \pm 6.22$ & $16.91 \pm 6.40$ & -4.63 & $.01 * *$ \\
\hline Balance (sec) & $19.80 \pm 7.01$ & $31.14 \pm 9.23$ & -3.70 & $.01 * *$ \\
\hline $\begin{array}{l}\text { Muscular Endurance } \\
\text { (frequency) }\end{array}$ & $28.32 \pm 7.50$ & $28.40 \pm 6.90$ & -.13 & .89 \\
\hline
\end{tabular}

Table 5. Mental Health Analysis $(\mathrm{N}=40)$

\begin{tabular}{|c|c|c|c|c|}
\hline \multirow{2}{*}{ Categories } & \multicolumn{2}{|c|}{ Mean \pm SD } & \multirow{2}{*}{$\mathrm{t}$} & \multirow{2}{*}{$\mathrm{p}$} \\
\hline & Before & After & & \\
\hline Sense of Isolation & $2.20 \pm .51$ & $1.53 \pm .52$ & 6.50 & $.01 * *$ \\
\hline Depression & $2.40 \pm .63$ & $1.52 \pm .31$ & 9.11 & $.01^{* *}$ \\
\hline Sociality & $2.81 \pm .70$ & $1.80 \pm .60$ & 6.75 & $.01^{* *}$ \\
\hline Interpersonal anxiety & $2.72 \pm .62$ & $1.61 \pm .43$ & 8.93 & $.01 * *$ \\
\hline
\end{tabular}

$* \mathrm{p}<.05, \quad * * \mathrm{p}<.01$ 
fitness and mental health. In other words, we studied how much aquatic group exercise could contribute to the enhancement of variables such as body composition, basic physical fitness and mental health. Detailed discussions are shown below.

Body Composition Analysis. According to the WHO, the usual results of being overweight and obese is the increased risk of cardiac diseases, cardiovascular diseases including stroke, and diabetes, as well as some kinds of cancer. It is also reported that the risk of such diseases increase proportionally with BMI. Mean BMI of participants in this study was 26.21 which fall under the first stage obesity. In this study, there was not a significant change in BMI. However, BMR and Body mass which plays an important role in the stage decreasing obesity, were significantly changed. The reason for insignificance in the reduction of BMI in this study seems to be because of insufficient time of participation such as 12 weeks or because they emphasized mental health and social relation improvement rather than exercise intensity to reduce obesity. For example, in the study by Jun et al. (2010) on the effects of a 24 week aquatic exercise program, the female elderly showed significant reduction in muscle amount, body fat rate and waist/hip circumference ratio, which at the period used in this study was twice the duration of this study. Considering significant reduction in BMR which is one of the most basic metabolisms in human body, it might be inferred that positive changes in BMR reduce obesity. Therefore long-term participation in aquatic group exercise might be expected to prevent obesity of the female elderly.

Basic Physical Fitness Analysis. There are many studies reporting that aquatic exercise improves basic physical strength of the elderly or patients requiring rehabilitation. Song et al. (2011) and Jang (2000) reported that aquatic exercise improved muscle strength, muscular skeletal endurance, sense of balance, and flexibility of arthritic patients (Song et al., 2011; Jung, 2009). Another study
(Kim et al., 2007; Kim et al., 2013) also reported that aquatic exercise improved most physical fitness factors of elderly females (Jung et al., 2009; Kim et al., 2007; Kim et al., 2013). The results of this study are consistent with previous studies showing positive effects on flexibility and sense of balance, but muscle strength and muscle endurance did not show significant difference although there was some change in mean value. The Flexibility and balance have been improved, but the reason why strength and endurance has not improved is probably because of the effect of buoyancy in water. It may be unfamiliar and uncomfortable for first time participants, who are unfamiliar with swimming pool buoyancy, to perform a variety of physical activities in the water and therefore their balance ability will gradually increase in time. These first time participants were immature in the program and lacked meaning for improving muscle strength or endurance. Moreover, as aquatic group exercise in pairs using interesting and entertaining programs however, exercise intensity may not have been enough to improve muscle strength and endurance or because of the limited period of 12 weeks.

Mental Health Analysis. Most of the elderly who are living in the city nowadays experiences diverse pressure and stress from a competitive life. Moreover, insufficient physical activities in their limited and depressed life environments tend to bring muscle deficiency (Frank et al., 1993). According to Buckworth and Dishman' study (2002), exercise affects depression regardless of gender, age, and health status. Another study done by Jang (2000) reported that while support and self-help groups, through exercise, form positive social relationships that improve their health recognition accuracy and provided emotional support and confidence to alleviate depression and anxiety. In this study, aquatic group exercise had effects on the sense of isolation, depression, sociality and interpersonal relationship, which is consistent with the study by Jang (2000). The elderly, who have made active and appropriate 
exercises recognized satisfaction and joy for the improved quality of life which resulted from attending such exciting physical activities (Kim et al., 2010).

To summarize, aquatic group exercise using various muscle groups with enjoyable music and strong recreation characteristics will activate the sympathetic system against stress, help the metabolism of muscles in the whole body (Mills et al., 1994), and play an important role in the confidence and mental health of the elderly by bringing energy metabolism changes in the central nervous system (Cho and Kim, 2012). Aquatic group exercise with graphic motions activates the cerebral cortex which has positive effects on body composition, physical fitness, and mental health so it is highly recommended for elderly population.

\section{Conclusion}

This study was conducted to identify the effects of 12 week aquatic group exercise program on body composition, basic physical strength, and mental health of the female elderly in their 60s and 80s. Conclusion and suggestions induced from the study are as follows.

First, it was found that the 12 week aquatic group exercise program produced effects on body composition in terms of body mass and BMR, which had a significant difference.

Second, it was found that the 12 week aquatic group exercise program produced effects on basic physical fitness of the female elderly participants. In the mean comparison, there was a little change in mean values of muscular strength, flexibility, sense of balance, and muscular endurance but only flexibility and sense of balance were significantly different.

Third, it was found that the 12 week aquatic group exercise program produced effects on the mental health of the female elderly participants. In the mean comparison, there was statistically significant difference in sense of isolation, depression, sociality, and interpersonal relationship anxiety.

When summarizing the above study results, it is suggested that aquatic group exercise programs be activated and encouraged to enhance the quality of life for the female elderly and various types of manuals should be developed according to the characteristics of individual programs to operate this exercise program more effectively.

\section{References}

Araki A, Murotani Y, Aoyagi Y. Comprehensive geriatric assessment and treatment of elderly diabetic patients. Nippon Ronen Igakkai Zasshi. Japanese Journal of Geriatrics. 2002;39(4):396-9.

Buckworth J, Dishman RK. Exercise psychology. Champaign, IL, Human Kinetics. 2002.

Cho SH, Kim CY. The Effects of training in exercise rehabilitation on depressive mood, BPSD in elderly with Alzheimer's Disease. J Korean Soc Phys Med. 2012;7(1):37-47.

Choe MA, Kim JI, Jeon MY, et al. Evaluation of the korean version of physical activity scale for the elderly (K-PASE). Korean J Women Health Nurs. 2010;16(1): 47-59.

Choi SH, Lim JH, Cho HY, et al. The Effects of trunk stabilization exercise using Swiss Ball and core stabilization exercise on balance and gait in elderly women. J Korean Soc Phys Med. 2012;7(1):49-58.

Frank P, Lee PP, Fullarton JE. Lifetime fitness and exercise for older people. San Francisco: Aging health policy center. University of California. 1993.

Jang SN. The Effects of aquatic exercise program on the physical function and depression in community elderly. J. Korea Community Health Nursing Academic Society. 2000;14(1):122-30. 
Jun JK, Lee WL, Park HG, et al. Effects of water exercise program for 24 weeks on the body composition, health related fitness, and quality of life in elders. Korean Academy of Kinesiology. 2010;12(3):25-33.

Jung DJ, Choi DE, Chung JW. The effect of aquarobics on metabolic syndrome risk factors in middle-aged women. J of Korean phys edu associ for girls and women. 2009;23(4):45-56.

Kay F, Barbara W, Eleanor RW. Exercise activities for the elderly. Springer P.C. New York. 1999.

Kim DS, Choi IS, Kim SY. The Impact of lower extremity strengthening exercise with step box and Elastic Band on balance ability and lower extremity muscular strength in community-living elderly individuals. J Korean Soc Phys Med. 2016;11(1):11-21.

Kim KH, Park SH, Huh Y. The Effects of swimming and aquarobic on middle-aged women's Body composition, physical fitness and blood lipid. Journal of Korea Sport Research. 2007;18(4):205-14.

Kim MJ, Kim KB. Influencing of psychological well-being for the middle aged adults and elderly. Journal of East-West Nursing Research. 2013;19(2):150-8.

Kim YC, Kim JW, Song YE, et al. The Effect of aquatic exercise program on body composition and heart rate variability in the middle aged obese women. $\mathrm{J}$ of Korea Soci for Wellness. 2013;8(3):220-9.

Lim HJ. A study on the body composition, physical activity level, basal metabolic rate, and daily energy expenditure of elderly in busan. Korean $\mathrm{J}$ of Commu Nutri. 2016;21(2):178-89.

McGill S. Low back disorders: evidence-based prevention and rehabilitation. Champaign, IL, Human Kinetics. 2002.

Mills K, Stewart AL, Sepsis P, et al. Older adults' physical activity preferences and their levels of adoption and maintenance. Annals of Beh Medi. 1994;16:S173.

Moon KS. The guidelines of aquatic exercise for beginner manual. Korea Sport Health Promotion Association. 2014.
Park IB, Ahn SY. The Effects of exercise with taping on muscle strength and bone mineral density, IGF-1 in blood of elderly women. J Korean Soc Phys Med. 2010;5(2):289-300.

Park ST, Hur SH, Lee JG, et al. Testing for validity of isometric muscle endurance test as an abdominal muscular endurance evaluation methods. Journal of the Korea Academia-Industrial cooperation Society. 2014; 15(2):815-27.

Reaven PD, Barrett-Connor E, Edelstein S. Relation between leisure time physical activity and blood pressure in older women. Circulation. 1991;83:559-65.

Resnick HE, Vinik AI, Schwartz AV, et al. Independent effects of peripheral nerve dysfunction on lower-extremity physical function in old age: the Women's Health and Aging Study. Diabetes Care. 2000;11:1642-7.

Rikli RE, Jones CJ. Senior fitness test manual. Champaign, IL, Human Kinetics. 2001.

So WY, Swearingin B, Crooms B, et al. The relationships between body composition measurements taken using BOD POD and eight-polar BIA were assessed using Pearson's r correlation. Health MED. 2012.

Song MS, Kim SK, Yoo YK, et al. Effects of the aquatic exercise program on body fat, skeletal muscle mass, physical fitness and depression in elderly women. J Korean Bio Nurs Sci. 2011;13(3):276-82.

Statistics Korea. 2015 Statistic Korea on the aged. Press release, Statistics Korea. 2015.

Washburn RA, Smith KW, Jette AM, et al. The physical activity scale for the elderly (PASE): development and evaluation. Journal of Clinical Epidemiology. 1993; 46(2):153-62.

Williams K, Haywood K, VanSant A. Force and accuracy throws by older adult performers. Journal of Aging and Physical Activity. 1993;(1):2-12.

WHO. What are common health consequences of overweight and obesity? World Health Organization. 2016.

WHO. Physical Activity and Old Adults. World Health 
Organization. 2016.

You YY, Lee BH. Effect of balance ability in the elderly women of motion-based game exercise program and stretching exercise program. J Korean Soc Phys Med. 2010;5(4):667-74. 